\title{
Recurrence of Atrial Septal Defect in Three Generations
}

\author{
Celso Ferreira, Leila M. S. Farah, Rui M. Póvoa, Bráulio Luna Fº, Andréa Costa, Celso Ferreira Fo \\ São Paulo, SP - Brazil
}

Beginning with a patient presenting with an atrial septal defect (ASD) of the secundum type, the genealogy was identified in four affected individuals who belonged to three successive generations of the same family. The defects were visually confirmed in all individuals and were found to be anatomically similar. No other congenital malformations were present in these individuals. The genealogy was identified in 1972, when ASD recurred in two generations, and it was concluded that the mechanism of transmission was autosomal recessive.

The fifth individual, identified 21 years later, and having an anomaly identical to that of the others, was the child of a couple who had no consaguinity and whose mother was a member of the previously studied genealogy.

Considering the absence of phenotype in the parents and the rarity of the ASD gene in the general population, the occurrence of the uniparental disomy for this family nucleus, and the same autosomal recessive mechanism of transmission by this affected individual is possible.

This study reports the familial occurrence of ASD by genetic mechanisms of transmission, emphasizing the necessity for genetic-clinical studies in members of the familial nucleus in order to detect new carriers, who usually are asymptomatic, thereby allowing for early and adequate treatment of individuals who may be affected.

The incidence of congenital heart diseases varies depending on the use of different diagnostic methods by different authors. From 1946 to 1953, 6053 children, including stillborns and newborns weighing $>500 \mathrm{~g}$, were seen at the Presbyterian Medical Center in New York. Fifty cases of congenital heart disease were present, which represents an overall incidence of 8.3 per 1000 , varying from $7.7 \%$ in stillborns and those who died in the first month to 6 in 1000 among those living more than a month. ${ }^{1}$ At our institution, Saldanha et $\mathrm{al}^{2}$ found an incidence of $3.4 \%$ of malformations in general among children born alive in the Hospital das Clínicas da Faculdade de Medicina da USP, São Paulo,

Universidade Federal de São Paulo - EPM

Mailing address: Celso Ferreira - Rua Leandro Dupret, 317 - 04025-011 - São Paulo, SP - Brazil

Received on: 10/29/98

Accepted on: 4/7/99
Brazil. The incidence of cardiac anomalies was 2.37 per 1000. Insley ${ }^{3}$ reports an incidence of 6 in 1000 of those born alive. Campbell ${ }^{4}$ believes that $10 \%$ correspond to ASD, giving an incidence of 0.6 per 1000 ASDs at birth.

The distribution of congenital heart diseases varies among different age groups; therefore, the prevalence is different from the incidence observed at birth. Campbell ${ }^{4}$ discussed this subject and compared his data about the preferential incidence in relation to sex, with that of Mac Mahon et $\mathrm{l}^{5}$ and Calgren ${ }^{6}$, with the prevalence reported by Keith et al. ${ }^{7}$ For ASD, the incidence at birth is $1: 1$, and it reaches $2: 1$ in the adult age, which is the prevalence of the disease.

Congenital anomalies, including congenital heart diseases, may be the result of endogenous abnormalities, that is, genetic abnormalities that occur either in microscopic or chromosomal anomalies or in submicroscopic or genetic anomalies. On the contrary, exogenous abnormalities represented by external teratogens, such as radiation or even viral infection during embryogenesis, can cause identical anomalies (phenocopies and genocopies).

Few studies exist that demonstrate the familial recurrence of ASD. Courter et al ${ }^{8}$, pioneers reporting the repetition of ASD without the association of other congenital heart abnormalities, included Lutembacher's syndrome in their publication. Although it can not be proved that they were the first ones to do so, the lack of previous reports identifies this as a seminal contribution. Gänsslen et al ${ }^{9}$ studied 68 pedigree diagrams from various congenital heart diseases and described the existence of evidence of recessive transmission in some of them, particularly those with patent ductus arteriosus and ASD. Courter et al ${ }^{8}$ reported two sisters with the clinical diagnosis of ASD without the association of other congenital heart defects. At the same time, rheumatic mitral regurgitation was found in both sisters, and they were reported as having Lutembacher's syndrome. Carleton et al ${ }^{10}$, based on the presentation of a single family, concluded that the mechanism of transmission was recessive; Howitt, ${ }^{11}$ also based on the presentation of a single genealogy, concluded that the type of transmission was dominant; Nora et al ${ }^{12}$ concluded that the mechanism was multifactorial; Zetterqvist et al ${ }^{13}$ agreed that the transmission was dominant based on three genealogies and Volti et al ${ }^{14}$ concluded the transmission was dominant. 
In his $\mathrm{PhD}$ thesis, Ferreira ${ }^{15}$ performed a genetic-clinical study of the isolated ASD of the secundum type in 8 genealogies and, due to the series of patients and the methodology used, he concluded that transmission was autosomal recessive.

The present study reports the occurrence of a fifth carrier of an identical anomaly, detected in the third consecutive generation in the same genealogy.

In 1972, a genetic-clinical study of isolated ASD of the secundum type was conducted at UNIFESP (São Paulo, Brazil) and the present genealogy was selected from among the eight studied genealogies.

The affected individual (III-9) (fig. 1), presenting with an ASD with significant hemodynamic compromise, was admitted to surgery, and the defect and its characteristics were confirmed at surgery. Starting with this patient, 24 individuals from this pedigree diagram were examined. They underwent routine clinical examinations, including electrocardiogram (ECG) and chest X-ray. When there was a suspicion of a cardiac defect, the patient was required to undergo a hemodynamic study. Three other patients were then detected as having ASDs and underwent surgery, which demonstrated an identical defect.

In 1993, another patient with congenital heart disease was admitted to UNIFESP. After a clinical examination, ECG, chest X-ray and echocardiogram, the recurrence of ASD was demonstrated, which was confirmed by surgery to be of the same anatomical type found in the other patients in the same genealogy with the defect. Beginning from this patient, parents and siblings were studied using the same methodology, and further recurrences were excluded.

In medicine, in order to treat any disease adequately, its etiology must be determined and this is usually very difficult for any congenital defect. As reported by Gordon ${ }^{16}$, who compared the mortality rate between deaths from diarrhea and congenital defects from 1910 to 1965 , an inversion has occurred in the relative importance of these two conditions as causes of death.

When heart diseases are considered, because it is very difficult to elucidate the etiology of congenital heart diseases and because there has been a major improvement in primary

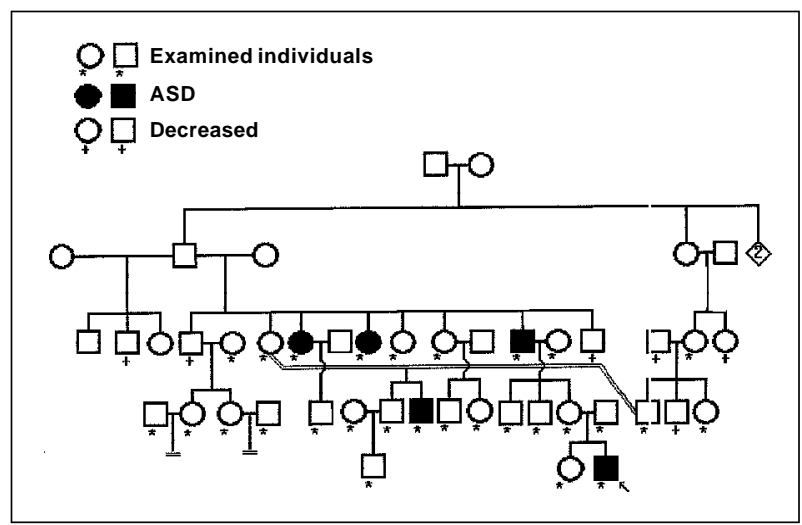

Fig. 1 - Pedigree diagram demonstrating the recurrence of atrial septal defect of the foss $a$ ovalis type in five individuals of three generations. and secondary prevention of acquired heart diseases, whose etiology is usually well defined, the genetic-clinical study of congenital heart diseases becomes even more relevant.

The main objection to the acceptance of a genetic hypothesis for congenital heart diseases was raised by studies among twins, which were performed in a way that can be criticized ${ }^{17-25}$. In monozygotic twins, identical in their genetic constitution, a higher occurrence of heart diseases should be found when compared with dizygotic twins, who are just brothers or sisters of the same age. These studies, however, did not demonstrate this difference. Nora et $\mathrm{a}^{26}$, however, in a review of the related literature, demonstrated that the results in twins support the genetic hypothesis for explaining congenital heart diseases. Eighty-eight monozygotic, 104 dizygotic and 78 twins in whom zygosis had not been previously established, were found. Thirty-six monozygotic and 41 dizygotic twins (a much smaller number than the one initially obtained) in whom the diagnoses of the zygosis and of the heart disease were accurate, were selected and some of their patients were included. Among these twins, concordance was much greater than that obtained by the previously cited authors, being $25 \%$ for monozygotic and $4.9 \%$ for dizygotic. With these results, genetic influence became evident, and the importance of the environment in determining congenital heart disease became incontestable.

Analyzing the observed recurrence in the present genealogy one can observe that only one horizontal line is present, which affected both females and males. Consanguinity was also present, thus suggesting an autosomal recessive mechanism. In the genetic-clinical study including the eight @ genealogies, the recurrence of defects of the atrial septum among brothers of patients with the defects was $11.5 \%$, standard deviation $6.3 \%$, when only patients who had a definite confirmation of the defect were included, and $16.7 \%$, standard deviation $6.8 \%$, when dead brothers with the possibility of having an ASD ${ }^{15}$ were also included. It is noteworthy that these results do not differ significantly from the expected proportions in recessive transmission, that is, three normal individuals for each affected person.

It must also be taken into consideration that this is the complement of a previous study, where six more genealogies were analyzed by the same methodology and, at that time, the above mentioned genetic mechanism was established ${ }^{15}$.

The recurrence of ASD in five patients in a single genealogy calls attention to a genetic etiology, even to observers who are less familiar with genetics. This possibility becomes even more evident when the incidence of the defect in the general population $(6: 10000)^{4}$ is compared with the significant recurrence in the present genealogy. On the other hand, it should also be noted that the defect was identical in all affected persons, emphasizing once more the genetic etiology.

The importance of the genetic-clinical study of patients with congenital heart diseases, here exemplified by ASD, is demonstrated by the identification of new patients who are detected by a systematic approach. Patient III-7, for example, 
died several years ago without a diagnosis suggestive of congenital heart disease (based on information obtained from close relatives) and with signs suggestive of hypertensive cardiomyopathy. Reviewing his hospital files was very helpful because they were very precise, and included a detailed description of the necropsy findings; not only the presence of the defect was mentioned, but there was also a description of its anatomical characteristics.

Patient III-8, born from the same consanguineous couple, was not aware of any cardiac problem, was asymptomatic and the diagnosis was the result of a systematic investigation that was carried out in this study.

The use of information obtained from hospital files and even from death certificates may, sometimes, be criticized because such documents are not always very precise. The consequent distortions secondary to an imprecise diagnosis do not allow this information to be accepted without vigorous analysis, which may lead to underestimation. This happened to one of our cases. Patient III-13 was asymptomatic, led an active life and was not aware of any cardiac problem. His hospital files during one admission for a minor surgery, described a normal heart examination. However, when he was examined during this study, particular attention was paid to the detection of a cardiac defect and the clinical diagnosis of ASD was made and then confirmed by surgery. Finally, the recurrence in patient V-3, who was sent to our institution with the diagnosis of an ASD (later confirmed by surgery), should be mentioned.

The identification of the fifth affected patient, born to a young, nonconsanguineous couple, lead to the clinical evaluation of his parents and sister, as well as to evaluation by ECG, chest X-ray and echocardiogram, and they were considered normal individuals.

The new recurrence made us reconsider the autosomal recessive mechanism, which had been previously admitted, because the progenitors were not consanguineous. For this transmission to occur, because the parents did not have the phenotype of ASD and according to classical knowledge on recessive transmission, it would be necessary for both to be heterozygotic of the gene. According to the pedigree chart, (figure 1) this would only be possible for the mother, with a very low probability for the father of the affected individual, considering the frequency of the gene in the general population. The coherent explanation for the fact is based on the hypothesis of the occurrence of the phenomenon of uniparental disomy. This mechanism, applied to this pedigree chart, would allow that only the mother of the V-3 patient, although with a normal phenotype, had the ASD gene in heterozygosis.

Uniparental disomy is a phenomenon that has been considered to explain the occurrence of recessive autosomal diseases in carriers in whom only one progenitor is heterozygotic for the gene in question ${ }^{27}$. This mechanism can result from the correction of a trisomy in an initial period of the embryological development, when two chromosomes from the mother (carrying the gene of the defect) and one from the father containing the normal gene (which would be eliminated), would be present. Another possibility would be the re-establishment very early in pregnancy of the disomic stage from a monosomy of the maternal chromosome, where the gene of the defect would be allocated, by the duplication of a single chromosome, characterizing an isodisomy of this chromosome.

Independent of the theories that may justify the recurrence of the defect, it is important to emphasize that, in the long-term, as the fourth generation enters the reproductive age and, taking into consideration that the observed penetrance and expression in the present pedigree diagram, it would be essential to perform a genetic-clinical evaluation to identify new affected patients. It is important to emphasize the necessity to search for new carriers, not only for a more precocious secondary prevention, but also to do primary prevention through genetic counseling in all situations where ASD seems to occur in a sporadic form.

\section{References}

1. Richards MR, Merrit KK, Samuels MH, Langmann AG. Congenital malformations of cardiovascular system in series of 6.053 infants. Pediatrics 1955; 15: 12-32.

2. Saldanha PH, Cavalcanti MA, LEMOS ML. Incidência de defeitos congênitos na população de São Paulo. Rev Paul Med 1963; 63: 211-29.

3. Insley J. The heretability of congenital heart disease. Br Med J 1987; 294: 662-3.

4. Campbell M. Causes of malformations of the heart. Br Med J 1965; 2: 895-904.

5. MacMahon B, McKeown T, Record RG. The incidence and life expectation of children with congenital heart disease. Br Heart J 1953; 15: 121-9.

6. Carlgren LE. The incidence of congenital heart diseases in children born in Gothenburg 1941 - 1950. Br Heart J 1959; 21: 40-50.

7. Keith JD, Rowe RD, Vlad . Heart Disease in Infancy and Childhood. New York: MacMillan, 1958: 129-32.

8. Courter SR, Felson B, Mc Guire J. Familial interauricular septal defect with mitral stenosis (Lutembacher's syndrome). Am J Med Sci 1848; 216: 501-8.

9. Gänsslen M, Lambrecht K, Werner M. Die kongenitalen Missbildungen des Herzen. Handbuch der Erbbiologie des Menschen. Bd. 4. Berlin: J. Springer, 1940: 198-217. Apud Lamy M, Grouchy J, Schwisgut ${ }^{18}$.

10. Carleton RA, Abelmann WH, Hancok EW. Familial occurrence of congenital heart disease. N Engl J Med. 1958; 259: 1237-45.
11. Howitt G. Atrial septal defect in three generations. Br Heart J 1961; 23: 494-6.

12. Nora J.J. Multifatorial inheritance hypotesis for the etiology of congenital heart diseases. Circulation 1968; 38: 604-17.

13. Zetterqvist P, Turesson I, Johansson BW, Laurell S, Ohlsson NM. Dominant mode of inheritance in atrial septal defect. Clin Genet 1971; 2: 78-86.

14. Li Volti S, Distefano G, Garozzo R, Romeo MG, Sciacca P, Mollica F. Autosomal dominant atrial septal defect of ostium secundum type. Ann Génét 1991; 34: 14-18.

15. Ferreira C. Estudo genético-clínico da comunicação interatrial do tipo defeito da fossa oval. - Tese de doutoramento - UNIFESP,1972.

16. Gordon H. Gennetic counseling. Considerations for talking to parents and prospective parents. JAMA 1971; 217: 1215-25.

17. Lamy M, Grouchy J, Schwisgut $\mathrm{O}$. Genetic and nongenetic factors in etiology of congenital heart disease: study of 1.188 cases. Am J Hum Genet 1957; 9: 17-41.

18. Drogamaci I, Green H. Factors in etiology of congenital heart anomalies. J Pediat 1947; 30: 295-301

19. Mc Aleese J.J. Survey of congenital heart disease in children's hospital with special reference to surgical treatment. Am J Surg 1952; 83: 755-60.

20. Holman E, Gerbode F, Purdy A. Patent ductus: review of 75 cases with surgical 
Ferreira et al.

Arq Bras Cardiol

Recurrence of atrial septal defect

volume 73, ( $\left.{ }^{\circ} 2\right), 1999$

treatment including aneurysm of ductus and one pulmonary artery. J Thorac Surg 1953; 7: 111-42.

21. Anderson RC. Causative factors underlying congenital heart malformations: patent ductus arteriosus. Pediatrics 1954; 14: 143-51.

22. Uchida TA, Rowe RD. Discordant heart anomalies in twins. Am J Hum Genet 1947; 9: 17-41.

23. Ross LJ. Congenital cardiovascular anomalies in twins. Circulation 1959; 20: $327-42$.
24. Campbell M. Twins and congenital heart disease. Acta Genet Med (Roma) 1961; 10: 443-56

25. Fuhrmann WH. Genetische únd peristatische Ursachen angeborener Angiokardiopathien. Ergebn Inn Med Kinderheilk 1962; 18: 47-115.

26. Nora JJ, Gilliland JC, Sommerville RJ, McNamara DG. Congenital heart disease in twins. N Engl J Med 1967; 277: 568-71.

27. Engel E. Uniparental dissomy revised: the first twelve years. Am G Med Genet 1993; 46: 670. 